\title{
Feasibility Assessment of an 8-week Attention- based Training Programme in the Management of Chronic Spontaneous Urticaria
}

Katie Elizabeth Ridge ( $\boldsymbol{\sim}$ katieelizabethridge@gmail.com )

Immunology Department, St. James's Hospital, Dublin 8, Ireland, Department of Immunology, Trinity College Dublin https://orcid.org/0000-0003-4276-7050

Niall Conlon

Saint James's Hospital

Martina Hennessy

Saint James's Hospital

Pádraic J Dunne

Royal College of Surgeons in Ireland

Research

Keywords: Chronic spontaneous urticaria, meditation, attention-based training, stress

Posted Date: October 15th, 2020

DOl: https://doi.org/10.21203/rs.3.rs-91630/v1

License: (c) (i) This work is licensed under a Creative Commons Attribution 4.0 International License. Read Full License

Version of Record: A version of this preprint was published at Pilot and Feasibility Studies on May 3rd, 2021. See the published version at https://doi.org/10.1186/s40814-021-00841-z. 


\section{Title page:}

Feasibility assessment of an 8-week Attention-based Training programme in the management of chronic spontaneous urticaria

Ridge Katie ${ }^{1}$, Conlon Niall ${ }^{1}$, Hennessy Martina², Dunne Pádraic J³.

\footnotetext{
${ }^{1}$ Immunology Department, St. James's Hospital, Dublin 8, Ireland, Department of Immunology, Trinity College Dublin

${ }^{2}$ Clinical Research Facility, St. James's Hospital, Dublin 8, Ireland.

${ }^{3}$ Centre of Positive Psychology and Health, Royal College of Surgeons Ireland, Dublin 2, Ireland.
} 


\section{Abstract}

Background: Chronic spontaneous urticaria is a common disorder that is poorly understood and frequently misdiagnosed. Psychological difficulties are a significant factor in dermatological diseases and may also aggravate symptom burden. Mind-body interventions are used as a complementary approach to alleviate symptoms in chronic diseases and may represent a valuable nonpharmacological approach in CSU.

Methods: We sought to develop and evaluate the feasibility of an 8-week Attention-based Training ( $A B T$ ) programme, coupled to biofeedback technology for CSU. Through convergent interviews, we gathered information from individuals with urticaria about possible links between stress, mood and skin symptoms. Using these data, we recruited 12 participants to engage in an amended $A B T$ programme for patients with $\mathrm{CSU}$, comprising eight ninety minute sessions held weekly. Participants completed psychometric measures and measures of urticaria symptomatology prior to and after the intervention. Adherence to ABT practice was measured using individual Inner Balance devices which tracked heart rate variability. We completed qualitative interviews after the intervention to obtain feedback on participant experience of the programme.

Results: Participants with CSU described how their psychological wellbeing can be linked to skin symptoms, poor sleep and difficulty concentrating. An amended ABT programme was found to be an acceptable component of care in the management of CSU. Retention of participants in the programme was challenging with $33 \%$ participants dropping out of the programme. For those who did complete the programme, adherence to ABT practice was impressive with $25 \%$ of participants exceeding weekly practice at week 8 . A statistically significant fall in severity of urticaria symptomatology was observed upon completion of the 
intervention $(\bar{x}=12.3$ SD 3.3, $\mathrm{p}<0.03)$. The most commonly cited barrier to implementation of the programme was the time commitment required.

Conclusions: An ABT programme can be integrated into clinical care for CSU patients and is valued by individuals who take part. Further formal evaluation of ABT for $\mathrm{CSU}$ including the analysis of biochemical parameters is required to determine its role in the management of this distressing condition.

Keywords: Chronic spontaneous urticaria, meditation, attention-based training, stress 


\section{Introduction}

Chronic spontaneous urticaria (CSU) is a skin condition characterised by recurring episodes of wheals, angioedema or both lasting longer than 6 weeks. It is a disorder that can be difficult to treat with up to $40 \%$ of patients having disease that is refractory to standard treatments (1). Patients often present with significant psychological difficulties accompanying their disease and this finding is reflected in the literature (2-4). Individuals with CSU have been shown to have significantly higher levels of self-reported depression and anxiety when compared to individuals without the disease (5). In addition, impaired quality of life in CSU has been found to correlate with disease activity (6). CSU has also been associated with reduced productivity and absenteeism at work as well as sleep interference $(7,8)$. It remains unclear as to whether psychological distress is a consequence of the disease, or whether there is a link between psychological morbidity and the development of urticaria.

Mind-body interventions are not currently considered part of conventional treatments for CSU but have been combined with mainstream therapies in other dermatological diseases as part of a complementary approach. In conditions such as psoriasis, the role of stress and mood as a trigger of symptoms is long recognised. There is some evidence that meditation can lead to improved clinical outcomes in patients with psoriasis either used in isolation or when combined with traditional treatments $(5,8,9)$. Similarly, in atopic dermatitis, psychological approaches such as relaxation training and stress management have been used to reduce itch intensity, scratching and disease severity $(7,10)$. 
Attention based training ( $A B T$ ) is based on the practice of mantra meditation and can be taught within a short timeframe (11). Most recently, it has successfully been used as a non-pharmacological intervention to reduce burnout and improve sleep, immune regulation and heart rate variability in Emergency Department staff (11). Mantra meditation, which is part of an ABT approach, has also been found to have utility in non-clinical populations (12).

\section{$\underline{\text { Objectives }}$}

This study sought to examine whether delivering a course in attention based training to individuals with CSU would be deemed acceptable and beneficial by participants.

\section{Primary outcomes}

- Identification of barriers to implementation of the intervention through convergent interviewing techniques

- Recruitment and retention of participants

- Adherence to daily practice using individual biofeedback tools

- Feasibility of collecting outcome assessment data

- Qualitative assessment of participant experiences of the programme after completion

\section{Secondary outcomes}

- Changes from baseline in perceived individual symptoms using the urticaria control test (UCT), post 8-week ABT programme

- Changes from baseline in depression, anxiety and stress using the depression-anxiety-stress score (DASS), post 8-week ABT programme 
- Changes from baseline in bio-psycho-social health using the PERMAprofiler, post 8-week ABT programme

- Changes from baseline in traits (attention, observational skills, nonreactivity and non-judgemental skills) associated with sustained meditation practice using the five-facet mindfulness questionnaire (FFMQ), post 8week ABT programme.

\section{Methods}

\section{Design}

This prospective single site study sought to assess the feasibility and acceptability of an eight week ABT programme for patients with CSU. The programme was completed in 2020 in a large teaching hospital in the Republic of Ireland. The study was conducted in accordance with guidelines for non-pharmacological clinical trials by the Consolidated Standards of Reporting Trials (CONSORT) group (13). Institutional ethics committee approval was in place from the SJH/AMNCH Research Ethics Committee Secretariat.

\section{Participants}

We recruited twelve adults with a diagnosis of chronic urticaria with or without angioedema who had symptoms on at least one day per week and an urticaria control test score of $<12$ indicative of poorly controlled symptoms (14). We excluded patients who had started an anti-depressant medication in the past 3 months or who had a diagnosis of an Axis I mental health disorder. 


\section{Outcome assessment data: Psychometric measures}

Participants were invited to complete the Depression and Anxiety Stress Scale (DASS 21)(15), the PERMA profiler (16) and the Five Facets of Mindfulness Questionnaire (FFMQ) (17) one week prior the intervention (Time 1) and one week after the intervention (Time 2).

\section{Convergent interviewing protocol}

Participants were invited for an initial interview to examine how patients felt about the current status of their disease and the impact of internal and external stressors on their symptoms. We used convergent interviewing which represents a qualitative research technique to identify key aspects of an unknown process (18) such as stressful triggers of CSU symptoms. Convergent interviewing involves initially unstructured interviews lasting one hour in duration to explore the research problem. After each interview, the transcripts were analysed and classified according to emerging themes. These themes were then integrated into the next interview in order to converge on the evolving themes in the topic area (19). New potentially converging themes are sense-checked with subsequent interviewees to confirm or reject them.

Seven patients diagnosed with CSU agreed to take part in one to one interviews with a qualified psychologist. Interviews were recorded and later transcribed; audio recordings were destroyed once the patients had approved their transcripts. A set of five questions were introduced at various stages during the first interview, based on themes noted in the current research literature $(20,21)$. The five questions were: 
1. Do you believe stress causes your symptoms?

2. Are early life stressful incidents linked to your symptoms?

3. Have you noticed the re-triggering of symptoms later in life by a stressor?

4. Have you any diagnosed allergies?

5. Is sleep an issue for you?

\section{Eight-week ABT programme}

The subsequent convergent themes common to the majority of the interviewees were used to inform and amend the existing ABT programme manual. The goal was to address the specific issues experienced by CSU patients in a bespoke ABT programme.

Recruited participants were invited to attend 8 consecutive, weekly ABT sessions, lasting 1 hour and 30 minutes, facilitated by a qualified psychologist trained in ABT facilitation. Participants were asked to begin practicing ABT twice daily for 2 minutes at each sitting, 7 days a week (28 minutes total for week one). Practice times were incrementally increased each week culminating in a recommendation to practice for 10 minutes, twice daily, 7 days a week (140 minutes total for week 8).

Participants were provided with individual biofeedback devices (Inner Balance by HeartMath UK) as an objective measure of practice adherence. The ABT programme used mantra meditation to help disengage from thoughts, memories, emotions and symptoms. Subsequent weekly themes included: developing a sustainable new habit, cultivating acceptance and self-compassion, managing distractions and self-judgement, core beliefs, negative automatic thinking, sleep 
hygiene, the importance of exercise and the managing of checking behaviours and intense symptoms.

\section{Practice adherence}

Adherence to daily practice was measured using individual Inner Balance devices (HeartMath UK). Inner Balance devices measured the duration (minutes) and quality of daily practice (coherence of heart rate variability in beats per minute over time). Researchers had access to practice data via EmWave software (HeartMath UK) from consenting participants. Individual practice adherence was openly discussed during each ABT session.

\section{Trial feasibility}

Enrolment logs were recorded for all participants who met eligibility criteria. We sought to recruit a minimum of ten participants to the programme. Practice adherence was measured as previously described.

\section{Post intervention semi-structured qualitative interviews}

As part of the evaluation of the ABT programme, a subset of three participants were randomly selected to complete a qualitative interview. This interview was conducted by an independent researcher and was designed to elicit barriers and facilitators to engaging with the 8 week $A B T$ programme. Participants were also invited to comment on the use of technology in the programme and provide feedback on how the programme was run. 


\section{Statistical analysis}

Statistics were calculated using GraphPad Prism software. Mean and standard deviation values are denoted as follows: $(\mathrm{x}=\bar{x}[\mathrm{y}])$. Paired and unpaired t-tests (denoted as $p$ values) were used to examine intra and inter-group differences. Power calculations were not calculated for this feasibility study due to insufficient existing data.

\section{Results}

\section{Baseline characteristics}

Twelve participants initially consented to participate in the programme (9F:3M). The age of participants ranged from $27-73$ years $(\bar{x}=49, \mathrm{SD}=13.4)$. One patient also had a diagnosis of cholinergic urticaria. All others had chronic spontaneous urticaria and angioedema. Medications for urticaria are listed in Table 1. Two patients were being treated with omalizumab.

\begin{tabular}{|l|l|}
\hline \multicolumn{2}{|l|}{ Table 1: Baseline characteristics of sample, $\mathbf{n}=\mathbf{1 2}$} \\
\hline Mean age (range) & 49 years $(27-73)$ \\
\hline Female gender & $9(75.0 \%)$ \\
\hline Prescribed at least 2 anti-histamines & $5(41.7 \%)$ \\
\hline Prescribed omalizumab & $2(17.4 \%)$ \\
\hline Mean serum IgE (s) & $236.5 \mathrm{kU} / \mathrm{I}(384.39)$ \\
\hline Mean Baseline UCT score & 7 \\
\hline
\end{tabular}

\section{Convergent interviews in CSU}

Table 1 illustrates the most commonly expressed themes in convergent interviews with demonstrative quotes. The majority of participants $(71.4 \%)$ felt that stress acted as a trigger for their urticaria. Participants voiced a frustration with medical treatments $(85.7 \%)$ and four respondents $(57.1 \%)$ had engaged in complementary therapies in an attempt to manage their symptoms. Forgetfulness and family issues with one or both parents (e.g. alcoholism) were noted for the 
majority of interviewees. Additionally, $57.1 \%$ of interviewees voiced issues with restlessness, poor focus, over-thinking and checking-behaviour (e.g. repeated checking whether appliances were left on or not). Interestingly, all seven interviewees used the phrase, "You just have to get on with it", in relation to tolerating their symptoms. This stoicism and general lack of self-compassion was apparent for all participants (Table 1 ). The ABT programme was subsequently amended with particular emphasis on cultivating focus, present moment awareness, self-compassion and managing checking behaviour. 


\section{Table 2. Themes emerging from each round of convergent interviewing of 7 participants diagnosed with CSU.}

\begin{tabular}{|c|c|c|}
\hline $\begin{array}{l}\text { Common themes emerging over } \\
7 \text { interviews }\end{array}$ & $\begin{array}{c}\text { Affirmative } \\
\text { response to } \\
\text { questions }(n, \%)\end{array}$ & Representative quotes \\
\hline $\begin{array}{l}\text { Do you believe stress causes your } \\
\text { symptoms? }\end{array}$ & $5,71.4 \%$ & $\begin{array}{l}\text { "My urticaria is really stress-induced, a lot. Mostly stress } \\
\text { induced or if I over-exert myself, like exercise too much." }\end{array}$ \\
\hline $\begin{array}{l}\text { Early life stressful incident linked to } \\
\text { symptoms }\end{array}$ & $5,71.4 \%$ & $\begin{array}{c}\text { "Very notable in my teens. I grew up in a family with alcoholism } \\
\text { and Alzheimer's under the one roof which is not easy. Plus } \\
\text { bullying at school." }\end{array}$ \\
\hline $\begin{array}{l}\text { Re-triggering of symptoms later in } \\
\text { life by a stressor }\end{array}$ & $5,71.4 \%$ & $\begin{array}{c}\text { "It came again later with stress in college; house issues; partner } \\
\text { split." }\end{array}$ \\
\hline $\begin{array}{l}\text { Diagnosed allergies present } \\
\text { including asthma }\end{array}$ & $6,85.7 \%$ & \\
\hline Is sleep an issue? & $6,85.7$ & \\
\hline \multicolumn{3}{|c|}{ Themes emerging from first round interview \% } \\
\hline Frustration with medical treatment & $6,85.7 \%$ & $\begin{array}{c}\text { "I suppose the length of time before I got to come in and see } \\
\text { anybody, that doesn't help either." } \\
\text { "It plays on your mind. Current medication Anti-histamines are } \\
\text { not really working." }\end{array}$ \\
\hline Stoicism/lacking self-compassion & $7,100 \%$ & "You just have to get on with it; nobody will listen anyway" \\
\hline Eldest in family & $2,28.6 \%$ & \\
\hline Most responsible in family & $6,85.7 \%$ & \\
\hline $\begin{array}{l}\text { Strong internal critic "oughts and } \\
\text { shoulds" statements predominate }\end{array}$ & $3,42.8 \%$ & \\
\hline \multicolumn{3}{|c|}{ Themes emerging from second round of interviews } \\
\hline Alternative therapy used & $4,57.1 \%$ & $\begin{array}{c}\text { "I tried Yoga and Pilates and I can't stand them because you } \\
\text { have to be quiet and you don't interact with people. I don't like } \\
\text { that." }\end{array}$ \\
\hline No strong support & $3,42.8 \%$ & "I don't have the support that I really need." \\
\hline A worrier & $2,28.6 \%$ & \\
\hline Forgetful & $5,72.4 \%$ & \\
\hline Checking behaviour & $4,57.1 \%$ & $\begin{array}{l}\text { "I regularly check things are turned off: light switches, cookers } \\
\text { etc. It's as if I'm on autopilot at times. If I've other things on } \\
\text { my mind, I'm distracted." }\end{array}$ \\
\hline Exhausted much of the time & $3,42.8 \%$ & \\
\hline Parent or family issues? & $5,71.4 \%$ & \\
\hline \multicolumn{3}{|c|}{ Themes emerging from third round of interviews } \\
\hline $\begin{array}{l}\text { In your family, who gets the } 2 \text { am } \\
\text { call (responsibility)? }\end{array}$ & $3,42.8 \%$ & "I usually get the call when things happen." \\
\hline Depression & $2,28.6 \%$ & \\
\hline Forgetful of names? & $3,42.8 \%$ & \\
\hline \multicolumn{3}{|c|}{ Themes emerging from fourth round of interviews } \\
\hline Restlessness & $4,57.1 \%$ & $\begin{array}{l}\text { "I can never relax or sit down. It always has to be me doing } \\
\text { something. Being bored is the worst. Hate that. Constantly } \\
\text { thinking about the next day. What am I going to do tomorrow? I } \\
\text { know that I'm going a million miles an hour all the time. I need } \\
\text { to relax." }\end{array}$ \\
\hline Poor Focus & $4,57.1 \%$ & \\
\hline Overthinking & $4,57.1 \%$ & \\
\hline Are you organised? & $2,28.6 \%$ & \\
\hline
\end{tabular}




\section{Trial feasibility: Recruitment and retention}

Out of the twelve participants who consented to participate in the ABT programme, eight participants completed the programme (attending at least 6 of 8 sessions) (See Table 2 below). The most commonly cited reason for drop out was the time commitment required by the programme.

Table 2 Retention and attendance statistics. Participants were only available to attend 6 out of 8 sessions, due to restrictions as a result of the COVID-19 pandemic in March 2020.

\begin{tabular}{|c|c|c|c|c|c|c|c|c|c|}
\hline \multicolumn{10}{|c|}{ WEEK 1} \\
\hline PARTICIPANT & 1 & 2 & 3 & 4 & 5 & 6 & 7 & 8 & $\begin{array}{c}\% \\
\text { attendance }\end{array}$ \\
\hline CU1 & $x$ & $x$ & $x$ & $x$ & $x$ & $x$ & & & 100 \\
\hline CU2 & $x$ & $x$ & $x$ & $x$ & $x$ & $x$ & & & 100 \\
\hline CU3 & $x$ & $x$ & $x$ & $x$ & $x$ & $x$ & & & \\
\hline CU4 & $\mathrm{x}$ & & $x$ & $\begin{array}{l}\text { drop- } \\
\text { out }\end{array}$ & $\begin{array}{l}\text { drop- } \\
\text { out }\end{array}$ & $\begin{array}{l}\text { drop- } \\
\text { out }\end{array}$ & $\begin{array}{c}\text { drop- } \\
\text { out }\end{array}$ & $\begin{array}{l}\text { drop- } \\
\text { out }\end{array}$ & - \\
\hline CU5 & $x$ & $x$ & $x$ & & $x$ & $x$ & & & 83 \\
\hline CU6 & $x$ & $x$ & $\begin{array}{l}\text { drop- } \\
\text { out }\end{array}$ & $\begin{array}{l}\text { drop- } \\
\text { out }\end{array}$ & $\begin{array}{l}\text { drop- } \\
\text { out }\end{array}$ & $\begin{array}{l}\text { drop- } \\
\text { out }\end{array}$ & $\begin{array}{c}\text { drop- } \\
\text { out }\end{array}$ & $\begin{array}{l}\text { drop- } \\
\text { out }\end{array}$ & \\
\hline CU7 & $x$ & $x$ & $x$ & $x$ & & & & & 67 \\
\hline CU8 & $x$ & $x$ & $x$ & $x$ & $x$ & $x$ & & & 100 \\
\hline CU9 & $x$ & $x$ & $\begin{array}{l}\text { drop- } \\
\text { out }\end{array}$ & $\begin{array}{l}\text { drop- } \\
\text { out }\end{array}$ & $\begin{array}{l}\text { drop- } \\
\text { out }\end{array}$ & $\begin{array}{l}\text { drop- } \\
\text { out }\end{array}$ & $\begin{array}{c}\text { drop- } \\
\text { out }\end{array}$ & $\begin{array}{l}\text { drop- } \\
\text { out }\end{array}$ & \\
\hline CU10 & & $x$ & $x$ & $\begin{array}{l}\text { drop- } \\
\text { out }\end{array}$ & $\begin{array}{l}\text { drop- } \\
\text { out }\end{array}$ & $\begin{array}{l}\text { drop- } \\
\text { out }\end{array}$ & $\begin{array}{c}\text { drop- } \\
\text { out }\end{array}$ & $\begin{array}{l}\text { drop- } \\
\text { out }\end{array}$ & \\
\hline CU11 & $x$ & $x$ & $x$ & $\mathrm{x}$ & $x$ & $x$ & & & 100 \\
\hline CU12 & $x$ & & $x$ & $x$ & $x$ & $x$ & & & 83 \\
\hline
\end{tabular}

\section{Practice adherence}

For participants who completed the intervention, practice adherence was monitored using individual Inner Balance devices and EmWave software (both by HeartMath, UK). Summary values were calculated from weeks 2 to 8 . Weekly practice targets over a 7 week period (in minutes) were: $28,42,56,70,84,98$ and 112. Although weekly practice tapered toward the end of the programme, $42.8 \%$ participants exceeded weekly practice targets when measured at week 8 (Fig. 1). The combined average practice adherence values (percentage of target) 
over the course of the ABT programme for all participants were: $61,140,83,73$, 73, 126, 106, 83, respectively. Participant 5 was ill and could not practice on weeks 5 and 6.

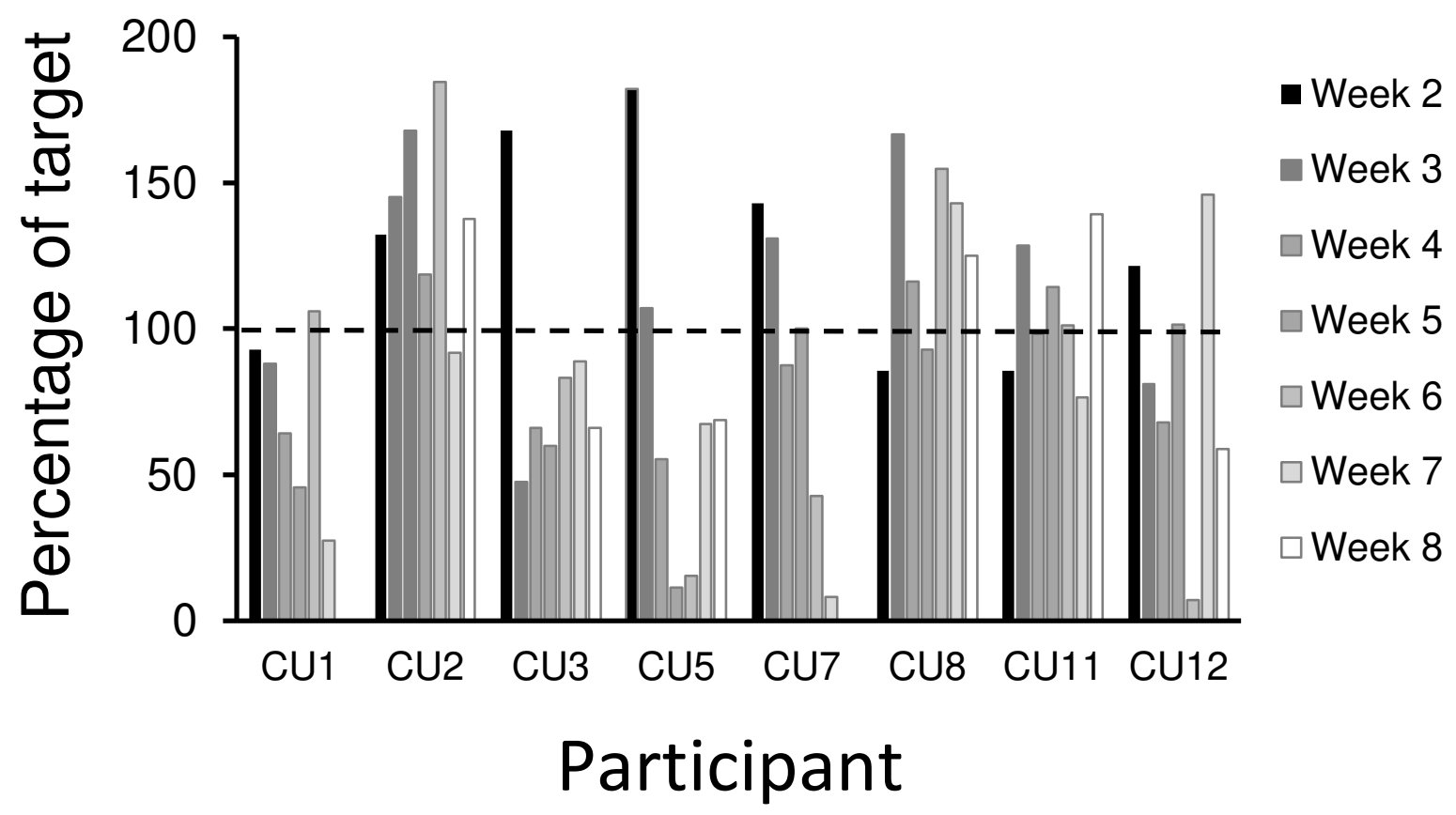

Figure 1. Adherence to weekly ABT practice. Adherence was measured using individual Inner Balance devices. Weekly practice targets over a 7 week period in minutes were: 28, 42, 56, 70, 84, 98 and 112.

\section{$\underline{\text { Psychometric measures and urticaria symptomatology }}$}

Table 3 demonstrates baseline data including Urticaria Control Test (UCT) scores, DASS 21, PERMA profiler and FFMQ scores for all participants at Time 1 . Time 2 data was returned for only seven participants. There was a statistically significant improvement in UCT scores between time 1 and time 2 for the participants who completed follow up $(\bar{x}=12.3$, SD $3.3, p<0.03)$. While there was an improvement in positive psychology attributes and a reduction in stress, anxiety and depression, these results were not statistically significant. 
Table 3. Urticaria symptomatology and psychological analysis of participants using three validated survey instruments before (time point 1) and after (time point 2) the 8-week ABT programme

\begin{tabular}{|c|c|c|c|c|}
\hline & $\begin{array}{l}\text { Number of } \\
\text { participants }\end{array}$ & $\begin{array}{c}\text { Time Point } 1 \\
\text { mean }(s d)\end{array}$ & $\begin{array}{c}\text { Time Point } 2 \\
\text { mean }(s d)\end{array}$ & $\mathrm{p}$ value \\
\hline \multicolumn{5}{|c|}{ URTICARIA CONTROL TEST } \\
\hline$<12=$ poor control & 4 & $6.7(3.6)$ & $12.3(3.3)$ & 0.03 \\
\hline \multicolumn{5}{|c|}{ DASS } \\
\hline DEPRESSION & 4 & $13.5(11.9)$ & $6(6.2)$ & 0.29 \\
\hline ANXIETY & 4 & $12.5(2.3)$ & $8(3.4)$ & 0.19 \\
\hline STRESS & 4 & $21.5(12.3)$ & $11(4.7)$ & 0.29 \\
\hline \multicolumn{5}{|c|}{ PERMA profiler } \\
\hline Positive emotion & 4 & $5.5(2.1)$ & $7(1.3)$ & 0.14 \\
\hline Engagement & 4 & $9.2(0.5)$ & $7.3(1.2)$ & 0.04 \\
\hline Relationships & 4 & $6.6(1.7)$ & 7.6 & 0.13 \\
\hline Meaning & 4 & $5.7(2)$ & $7.7(0.3)$ & 0.06 \\
\hline Accomplishment & 4 & $5.9(2.2)$ & $7.3(1)$ & 0.18 \\
\hline Overall wellbeing & 4 & $6.5(1.5)$ & $7.4(0.8)$ & 0.2 \\
\hline Negative emotion & 4 & 5.5. (3.1) & $3.7(0.6)$ & 0.16 \\
\hline Health & 4 & $3.8(1.4)$ & $4.7(1.2)$ & 0.09 \\
\hline Loneliness & 4 & $3.5(1.6)$ & $5.5(1.8)$ & 0.08 \\
\hline \multicolumn{5}{|c|}{ FFMQ } \\
\hline Observation skills & 4 & $22.5(2.7)$ & $25.3(2.5)$ & 0.04 \\
\hline Describing skills & 4 & $22.5(3.4)$ & $25.5(6.1)$ & 0.27 \\
\hline Awareness & 4 & $24.3(8.7)$ & $27.8(1.9)$ & 0.27 \\
\hline Non-judgemental & 4 & $23(10)$ & $29.8(4)$ & 0.15 \\
\hline Non-reactivity & 4 & $15.8(6.1)$ & $24.3(3.3)$ & 0.05 \\
\hline
\end{tabular}

Post intervention semi-structured qualitative interviews

Thematic analysis was used to identify key themes regarding barriers and facilitators to implementation (Table 4). Iterative discussion between two authors (KR and PD) refined analysis of themes. Summaries of findings were sent to the subset of participants for review; all affirmed the findings were accurate. 


\begin{tabular}{|c|c|}
\hline $\begin{array}{l}\text { Benefits of participation in the } A B T \\
\text { programme }\end{array}$ & $\begin{array}{l}\text { 'I found the therapy I would say very } \\
\text { good. I seem to be able to control the } \\
\text { flare ups...I find I'm not taking as much } \\
\text { anti-histamines either' } \\
\text { 'I found that it pushed me to go back } \\
\text { to doing twenty minutes (meditation) } \\
\text { morning and evening and I have stuck } \\
\text { to that' }\end{array}$ \\
\hline Meeting others with the same condition & $\begin{array}{l}\text { 'It was nice to sit there and listen to } \\
\text { other people's stories. It just gives you } \\
\text { a little bit of hope I think' } \\
\text { 'I was delighted to know that there was } \\
\text { other people with similar conditions to } \\
\text { what I have, because I thought that } \\
\text { there wasn't anyone' }\end{array}$ \\
\hline Barriers to participating in $\mathrm{ABT}$ & $\begin{array}{l}\text { 'Just being too busy, not finding the } \\
\text { time in the day' } \\
\text { 'Not managing to take the time in the } \\
\text { morning and the evening, I'm not } \\
\text { giving myself that time' }\end{array}$ \\
\hline Facilitators to participating in $\mathrm{ABT}$ & $\begin{array}{l}\text { 'The gizmo that we had - it did kind of } \\
\text { push you to do it because you know } \\
\text { you're being watched. It does make } \\
\text { you more conscious of doing it' } \\
\text { 'I found the technology helpful to learn } \\
\text { the technique of breathing' }\end{array}$ \\
\hline
\end{tabular}




\section{Discussion}

The current study sought to design an attention based training programme tailored towards patients with chronic spontaneous urticaria (CSU) and evaluate the feasibility of delivering this programme as part of clinical care. In order to create a programme that was relevant to this patient population, we used a convergent interview process to identify how individuals with urticaria understand links between their psychological wellbeing and skin symptoms. We sought to assess recruitment, retention and adherence of participants as well as changes from baseline in perceived individual symptoms of urticaria and psychological wellbeing prior to and post intervention. We conducted qualitative interviews with a subset of participants to understand their experience of the programme.

\section{Themes emerging from convergent interviewing in CSU}

There is growing evidence for the significant psychological burden of CSU and this was confirmed by participants in the current study who felt that stress was an important factor in their disease. Participants voiced difficulties pertaining to poor concentration and sleep. Depression, anxiety, reduced quality of life and disturbed sleep are well documented in this cohort $(2,4,6)$. In addition, participants in the current study voiced a frustration with medical treatments for CSU and a desire to seek alternative therapies. The challenge of treating individuals with urticaria, particularly non-responders, is apparent and has led to a trend towards trialling alternative pharmacological and nonpharmacological therapies in CSU (22). These findings highlight the importance of assessing the utility of a nonpharmacological approach that might address psychological and behavioural aspects of symptoms. 


\section{$\underline{\text { Recruitment, retention and adherence }}$}

While recruitment to this study was relatively straightforward, retention of participants was a challenge. The Covid 19 pandemic impacted upon our intervention in its final weeks caused a reluctance to attend. The most common reason for withdrawal from the programme was the time commitment required. However it is also a possibility that a meditation based programme may not appeal to all individuals with CSU. Despite this, for individuals who persisted with the programme, an impressive level of adherence to $A B T$ was demonstrated using biofeedback technology with all participants exceeding the weekly target of practice on at least one occasion.

\section{Perceived symptoms of urticaria and psychometric measures}

We observed a reduction in perceived individual symptoms of urticaria upon completion of the ABT programme which was statistically significant. Measures of depression, anxiety and stress fell for all participants who returned follow up data but this finding did not reach statistical significance. While we are reluctant to over emphasise our findings given our small sample size, we remain confident that at a minimum did not have a negative impact upon participant wellbeing and is worth further examination with a larger sample. Data obtained can be used to develop power calculations and inform study size. In addition, qualitive interviews performed upon completion of the programme indicate that the programme was well liked and would be valued as a component of clinical care. 


\section{Future development of the ABT programme}

We have identified a number of solutions to try and facilitate participants of future programmes. We envisage that some sessions could be carried out using a virtual format. We also anticipate that when the programme is being run at a more significant scale, participants will have more options in terms of when they can attend the programme. The preliminary positive effects of our programme despite it having to be cut short by two weeks indicate that benefits from the programme might be achievable within a shorter time frame. Designing and evaluating a programme that is shorter in duration might be more attractive in terms of participant recruitment and retention.

\section{Conclusion}

CSU is a disorder that has significant individual and societal effects. Psychological approaches have been used as a complementary treatment to clinical care in dermatological disease. This feasibility study sought to assess whether an attention based training programme could be successfully integrated into clinical care for patients with CSU. The programme was well tolerated with individuals reporting they felt they had benefited from taking part. In addition, we observed an improvement in psychological wellbeing and individual perception of urticaria symptoms in individuals who completed the programme. With only minor adjustment, we can assert that a randomised controlled trial to test the effectiveness of ABT as a component of CSU management will be feasible. 


\section{Declarations}

\section{Ethics approval}

This study had ethical approval. Institutional ethics committee approval was in place from the SJH/AMNCH Research Ethics Committee Secretariat.

\section{Consent for publication}

Participants gave informed consent to participate. This consent included consent to the publication of data.

\section{Availability of data and materials}

The datasets generated during the current study are/will be available upon request from the research team.

\section{Competing interests}

The research team have no financial or non-financial competing interests to declare.

\section{Funding}

The study did not receive external funding.

\section{Authors' contributions}

$\mathrm{KR}, \mathrm{PD}$ and $\mathrm{NC}$ were involved conception and design of the programme. $\mathrm{PD}$ delivered the programme. All authors were involved in manuscript preparation. MH undertook critical revision of the manuscript. 


\section{Acknowledgement}

The research team would like to acknowledge the Clinical Research Facility in St. James's Hospital, Dublin, for facilitating the study.

\section{Trial registration}

This trial is registered with ISRCTN with study ID ISRCTN13672947. Registration took place on 22/09/2020 (Retrospectively registered). The study can be viewed at http://www.isrctn.com/ISRCTN13672947 
1. Maurer M, Costa C, Gimenez Arnau A, Guillet G, Labrador-Horrillo M, Lapeere H, et al. Antihistamine-resistant chronic spontaneous urticaria remains undertreated: 2-year data from the AWARE study. Clin Exp Allergy. 2020.

2. Balp MM, Vietri J, Tian H, Isherwood G. The Impact of Chronic Urticaria from the Patient's Perspective: A Survey in Five European Countries. Patient. 2015;8(6):551-8.

3. Kang MJ, Kim HS, Kim HO, Park YM. The impact of chronic idiopathic urticaria on quality of life in korean patients. Ann Dermatol. 2009;21(3):226-9.

4. O'Donnell BF. Urticaria: impact on quality of life and economic cost. Immunol Allergy Clin North Am. 2014;34(1):89-104.

5. Kabat-Zinn J, Wheeler E, Light T, Skillings A, Scharf MJ, Cropley TG, et al. Influence of a mindfulness meditation-based stress reduction intervention on rates of skin clearing in patients with moderate to severe psoriasis undergoing phototherapy (UVB) and photochemotherapy (PUVA). Psychosom Med. 1998;60(5):625-32.

6. Maurer M, Abuzakouk M, Berard F, Canonica W, Oude Elberink H, Gimenez-Arnau A, et al. The burden of chronic spontaneous urticaria is substantial: Real-world evidence from ASSURE-CSU. Allergy. 2017;72(12):2005-16.

7. Bae BG, Oh SH, Park CO, Noh S, Noh JY, Kim KR, et al. Progressive muscle relaxation therapy for atopic dermatitis: objective assessment of efficacy. Acta Derm Venereol. 2012;92(1):57-61.

8. Gaston L, Crombez JC, Lassonde M, Bernier-Buzzanga J, Hodgins S. Psychological stress and psoriasis: experimental and prospective correlational studies. Acta Derm Venereol Suppl (Stockh). 1991;156:37-43.

9. Gamret AC, Price A, Fertig RM, Lev-Tov H, Nichols AJ. Complementary and Alternative Medicine Therapies for Psoriasis: A Systematic Review. JAMA Dermatol. 2018;154(11):13307.

10. Chida Y, Steptoe A, Hirakawa N, Sudo N, Kubo C. The effects of psychological intervention on atopic dermatitis. A systematic review and meta-analysis. Int Arch Allergy Immunol. 2007;144(1):1-9.

11. Dunne PJ, Lynch J, Prihodova L, O'Leary C, Ghoreyshi A, Basdeo SA, et al. Burnout in the emergency department: Randomized controlled trial of an attention-based training program. J Integr Med. 2019;17(3):173-80.

12. Lynch J, Prihodova L, Dunne PJ, O'Leary C, Breen R, Carroll A, et al. Mantra meditation programme for emergency department staff: a qualitative study. BMJ Open. 2018;8(9):e020685.

13. Eldridge SM, Chan CL, Campbell MJ, Bond CM, Hopewell S, Thabane L, et al. CONSORT 2010 statement: extension to randomised pilot and feasibility trials. BMJ (Clinical research ed). 2016;355:i5239.

14. Weller K, Groffik A, Church MK, Hawro T, Krause K, Metz M, et al. Development and validation of the Urticaria Control Test: a patient-reported outcome instrument for assessing urticaria control. J Allergy Clin Immunol. 2014;133(5):1365-72, 72 e1-6.

15. Lovibond PF, Lovibond SH. The structure of negative emotional states: comparison of the Depression Anxiety Stress Scales (DASS) with the Beck Depression and Anxiety Inventories. Behav Res Ther. 1995;33(3):335-43.

16. Ryan J, Curtis R, Olds T, Edney S, Vandelanotte C, Plotnikoff R, et al. Psychometric properties of the PERMA Profiler for measuring wellbeing in Australian adults. PLoS One. 2019;14(12):e0225932. 
17. Brown DB, Bravo AJ, Roos CR, Pearson MR. Five Facets of Mindfulness and Psychological Health: Evaluating a Psychological Model of the Mechanisms of Mindfulness. Mindfulness (N Y). 2015;6(5):1021-32.

18. Jepsen Denise $M$, Rodwell John J. Convergent interviewing: a qualitative diagnostic technique for researchers. Management Research News. 2008;31(9):650-8.

19. McClymont $\mathrm{H}$, Gow J, Hume M, Perry C. Factors influencing back pain treatment behaviour change. Journal of Service Theory and Practice. 2015;25(5):592-620.

20. Konstantinou GN, Konstantinou GN. Psychiatric comorbidity in chronic urticaria patients: a systematic review and meta-analysis. Clinical and Translational Allergy. 2019;9(1):42.

21. Ben-Shoshan M, Blinderman I, Raz A. Psychosocial factors and chronic spontaneous urticaria: a systematic review. Allergy. 2013;68(2):131-41.

22. Vena GA, Maurer M, Cassano N, Zuberbier T. Alternative treatments for chronic spontaneous urticaria beyond the guideline algorithm. Curr Opin Allergy Clin Immunol. 2017;17(4):278-85. 
Figures

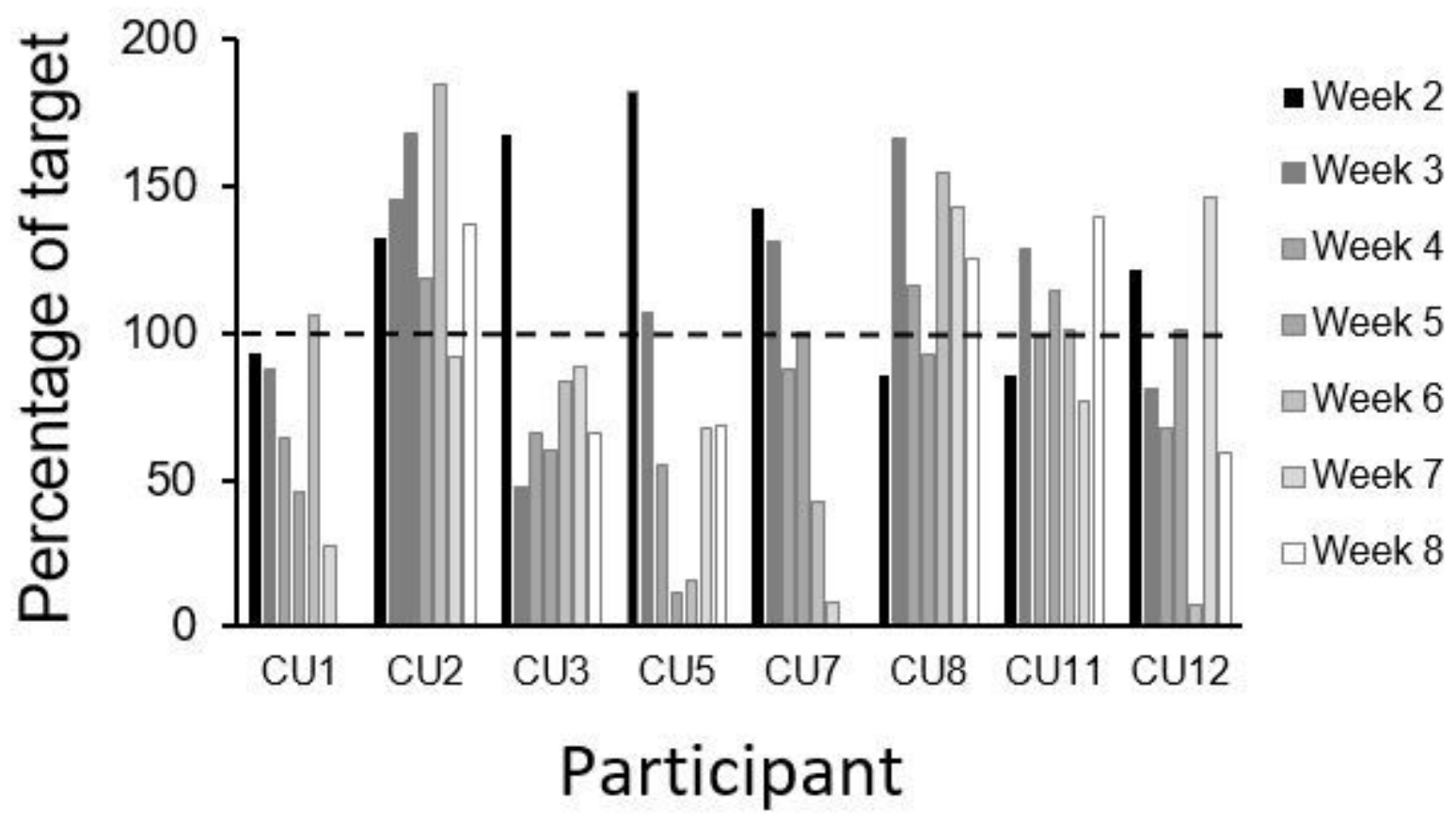

Figure 1

Adherence to weekly ABT practice. Adherence was measured using individual Inner Balance devices. Weekly practice targets over a 7 week period in minutes were: 28, 42, 56, 70, 84, 98 and 112.

\section{Supplementary Files}

This is a list of supplementary files associated with this preprint. Click to download.

- CONSORT.doc 